\title{
DAMASIO DE FRÍAS Y SU DÓRIDA, DIÁLOGO DE AMOR. EL ITALIANISMO EN VALLADOLID
}

La mayoría de los clásicos olvidados lo están justamente. A pesar de esta convicción común que comparto, intentaré refrescar la fama de un prosista castellano casi olvidado: Damasio de Frías y Balboa. Damasio, como le llamaban sus amigos poetas, fue un filósofo de capa y espada, un libre profesor peripatético -en su doble sentido de paseante y seguidor de Aristóteles- que sembraba sus opiniones y agudezas por las calles de su ciudad natal, entre la sala del conde de Ribadavia y el convento de Santa María de Prado. No pretendo hacer de él un Sócrates o Montaigne de Valladolid, sino salvar por un momento del olvido a un prosista, podríamos decir un ensayista, interesante e independiente.

Había frecuentado de muchacho las escuelas de Salamanca, seguramente las cátedras de filosofía, y adquirido el gusto por las discusiones apasionadas. Sirvió luego a un magnate que gustaba de su conversación: al almirante de Castilla don Luis Enríquez, duque de Rioseco y casado con doña Ana de Cabrera, condesa de Módica en Sicilia. El almirante y su esposa recibieron la dedicatoria de fray Luis de Escobar, Las quatrocientas respuestas a otras tantas preguntas, Valladolid, 1545, libro en verso en el cual don Fadrique Enríquez, el más famoso de los almirantes, había de cierto modo colaborado con las preguntas. La primera historia fechable de Damasio es su visita a la condesa de Gelves en Sevilla, poco después de su casamiento, por tanto en 1555: Damasio recordaba en 1579 cómo la futura musa de Fernando de Herrera y el mozo vallisoletano pudieron reír alegremente sobre la obsesión de un caballero, gobernador de uno de los estados del Conde, el cual a la tercer palabra comenzó a hablar de caballos y no supo salir de la caballeriza (Discreción, 185) ${ }^{1}$.

1 Enumero aquí las obras citadas en abreviatura: DaMasio de Frías, Diálogos de diferentes materias inéditos hasta ahora, Madrid, 1929 (Col. de escritores castellanos). Contiene tres que se abrevian así: 
Damasio gustaba de evocar sus recuerdos de cuando Valladolid era corte de España. Recordemos que en la ciudad vivían muchos italianos, entre ellos Juan Lorenzo Otavanti, el traductor al castellano de Savonarola y Maquiavelo; que los nobles españoles, entre ellos los parientes de su amo, trillaban los caminos de Italia. A la vuelta traían libros y palabras nuevas, con enojo de los casticistas que reprendían el abuso de aquellos españoles italianados los cuales, refiere Damasio "a cualquiera propósito, y aun muy sin él, por sólo que se entienda de ellos que han estado en Italia, usan del nombre italiano" (Lenguas, 212-213). Muy lejos de condenar vocablos como "abandonado", "al parangón", etc., Damasio defiende la necesidad de los neologismos, porque un casticismo estancado sería mero indicio de que no había comunicación con el resto del mundo.

En Valladolid conoció a los dos más discretos caballeros de la corte, don Diego de Azevedo y don Diego Hurtado de Mendoza que juntos mandaron, camino de Inglaterra, la flota castellana en 1557. Del "discretísimo" don Diego de Mendoza traza una doble semblanza: en la primera lamenta que "tal personaje, tan estimado de toda Italia y de los mejores de ella, como también de toda España, no tuvo con su Rey aquel lugar que merecía el valor de su persona y entendimiento" (Discreción, 11); en la segunda afirma que "ningún otro caballero de nuestros tiempos se halló de su mucha erudición, de su gran variedad y conocimiento de cosas, con una singular agudeza y una experiencia de tanto como había visto y de lo mucho que había al fin pasado por sus manos" (ibid., 90-91). Me he detenido un instante en Hurtado de Mendoza porque favoreció el italianismo de Damasio. Dos indicios me lo sugieren: 1) que el gran escritor granadino, según nos informa Daniel Barbaro en la dedicatoria de la edición aldina de los Dialoghi (1550), figuraba entre los protectores posibles de Speron Speroni, a quien Damasio seguiría y alabaría en Dórida; 2) que Fernando de Herrera asociaría los nombres del vallisoletano y el granadino como introductores en España de un subgénero italiano:

Discresión = "Diálogo de la discresión", pp. 3-210.

Lenguas = "Diálogo de las lenguas", pp. 211-276.

Dórida = "Diálogo de amor", pp. 277-388.

Abreviaré también:

Speroni $=$ Dialoghi di M. Speron Speroni, Vinegia, 1550, de los que menciono solamente el Diálogo d'amore, ff. $3 \mathrm{v}-30 \mathrm{v}$ y Diálogo delle lingue, ff. $87 \mathrm{v}-108 \mathrm{v}$.

León Hebreo = La traduzión del Indio de los tres "Diálogos de amor de León Hebreo... por Garcilasso Inga de la Vega. En Madrid, 1590; reproducida por Menéndez Pelayo, Origenes de la novela, Madrid, 1915, NBAE, t. 3, pp. 278-459. 
es decir, de la sátira literaria en forma de misiva. He aquí el pasaje de Herrera en la perversa transcripción en que nos licgó. Me refiero al reproducido en $F$. de H., Controversias sobre sus Anotaciones a las obras de Garcilaso de la Vega, Sevilla, 1870, p. 69, "Contestación a Prete Jacopín":

Estamos en tiempo donde no bale el crédito de opinıones grandes; cada uno piensa que save y que puede zensurar aun las obras qu'están seguras i fuera de toda ynvidia, i tienen ya estos críticos puesto el blanco en desalabar lo que unos estiman, y encarezer lo que bituperan otros. Mas perdone Dios a Don Diego de Mendoza aber traido de Ytalia este género d'escrebir. Porque dio atrevimiento a Damazio $[\mathrm{sic}]$ para dezir mal del Ynventario de Villegas, con aquel donaire que tiene en todas sus cosas, y después para juzgar estas Anotaziones en una muy prolija carta que enbió desde Balladolid a un platero qu'estaba en Sebilla, que a buena razon no debia ser tan letrado como V. R., con que os quitó la gloria de aver sido el primero Reprehensor dellas. Aunque, o sea la seguridad de conziencia o otra causa, F. de $\mathrm{H}$. a hecho dél el mesmo casso que de vos.

De estas sátiras literarias de Damasio, tan aplaudidas en su tiempo, nos ha llegado esta escueta noticia de Herrera. Extravío lamentable, porque su autor era un espíritu original y agudo. Su originalidad la proclama en Discreción, 67:

Sabéis ya cuán enemigo fui yo siempre de tratar en mis conversaciones o escritos cosas tratadas de otros formalmente y en propios términos, como bien podréis haberlo visto por todos mis diálogos apologias y discursos y en cuanto más escrito tengo. Por poco honroso tuve yo siempre con $\mathrm{mi}$ amigo Horacio caminar alguno con su ingenio por sendas y caminos hollados, nunca sentando el pie, sino en expresas y muy señaladas pisadas de otro.

Extraviada o perdida, con excepción de cuatro diálogos, toda su obra de prosista, no sabemos si aceptar la opinión de su interlocutor Phanio que le aclama como el mejor crítico de su tiempo (Discreción, 71):

... eso han notado en vos cuantos... os conocen, que sois sin comparación más excelente en el juicio de la poesía que en su composición, teniendo en ésta muchos por lo menos iguales y, como vos confesáis, con muchas ventajas superiores, donde en el juzgar de esta facultad, ninguno he visto que os reconozca: en romance, digo, que en latín ya vuestros amigos sabemos que nunca hecistes verso.

Bastantes pasajes de sus escritos inclinan, casi fuerzan, a suponer que recorrió las tierras de Italia. Por ejemplo, el largo intento 
de caracterizar las diferentes pronunciaciones desde Bérgamo y Venecia hasta Florencia y Siena o la comparación de Italia y España en el Diálogo en alabanza de Valladolid (Discreción, 268) ${ }^{2}$. Allí el Ciudadano -que seguramente representa a Damasio- afirma: "Es verdad que Italia sin contradicción alguna es tenida por la mejor de quantas provincias se saben en el mundo, y assí las ciudades todas suyas son a una mano las mejores" (p. 286). A sus viajes marítimos alude cuando compara al criado que sepa sortear los escollos de la servidumbre, con "muy plático y diestro piloto llevando su nao, como yo algunas veces vi en el Océano, por entre algunos isleos [sic] y bajíos" (Discreción, 118).

Pocos escritores, en la España de Felipe II, fueron más amigos de intercalar confidencias y recuerdos personales. Su personalidad irrumpe en sus diálogos (menos en el de Valladolid, donde su presencia es más velada) de modo terminante: en el de la Discreción y el de las Lenguas con su nombre explícito como interlocutor central, y en el de Dórida bajo el disfraz transparente de Dameo.

Dórida nos ofrece una tentativa, bastante afortunada, de traer a España el trattato d'amore, género híbrido de literatura y filosofía. La forma de diálogo añade la posibilidad de un leve movimiento dramático.

\section{LAS FORTUNAS DE DóRIDA}

Dórida renació en 1929, cuando el benemérito erudito Justo García Soriano publicó en un tomo los tres Diálogos de diferentes materias inéditos hasta ahora (una reseña de esta publicación hizo J. F. Montesinos, RFE, 19, 1932, 189-193, donde atribuye las muchas incorrecciones del manuscrito tanto a las torpezas del copista como al descuido y precipitación del autor). Francisco Rodríguez Marín, en una minúscula "Advertencia preliminar", calificaba a Damasio de "castizo y elegante prosista" y apuntaba acerca de sus diálogos que "de ellos solamente uno fue dado a los moldes de la

2 Reproducido por Narciso Alonso Contés, Miscelánea vallisoletana, t. 1, Valladolid, 1959, pp. 225-287. Antes se había publicado en la Miscelánea vallisoletana, Valladolid, 1919. El Diálogo en alabanza de Valladolid va precedido de 6 páginas de erudición en que Alonso Cortés recoge los testimonios coetáneos sobre la poesia de Damasio, es decir los de Lomas Cantoral, Cervantes en la Galatea (Canto de Caliope), Vicente Espinel en sus Rimas (Casa de la Memoria), y los elogios de López de Sedano en su Parnaso español, donde incluye cinco poemas de Damasio. Resume un curioso documento sobre la intervención de nuestro autor en la composición de "ystorias y letras" que decoraban un arco en la entrada de Felipe II en Valladolid, año de 1561. Por último señala la existencia del manuscrito de los Diálogos en la Biblioteca Nacional, pero no se interesa por el prosista. 
imprenta, y eso en fecha tan remota y en edición tan limitada que es hoy poco menos curioso y desconocido que los otros enteramente inéditos". No puntualizaba el misterio de la rara y recóndita impresión. La colección Clásicos olvidados (1928-1929) anunciaba al final de los ocho primeros volúmenes la reimpresión de "Diálogo de amor intitulado Dórida (Burgos, 1593). Edición y estudio de Miguel Artigas", prueba de que se trataba de un secreto a voces. Desgraciadamente Miguel Artigas nunca llevó a cabo la edición y estudio programados.

No era la primera malaventura que se ensañaba en Dórida, obra que la princeps daba como anónima, que Nicolás Antonio atribuiría a su editor, que otros colgarían dubitativamente a León Hebreo, y la Inquisición, por extraños rodeos, vendría a prohibir. Veamos los pormenores.

La imprimeria de Philippe de Iunta y Juan Bautista Varesio estampó en 1593 un librillo menudo de título atractivo: Diálogo de amor intitulado "Dórida". En que se trata de las causas por donde puede una amante (sin ser notado de inconstante) retirarse de su amor. Nuevamente sacado a luz, corregido y enmendado por luan de Enzinas, vecino de Burgos, Burgos, 1593. Aunque lleva al fın de ros preliminares un elegante soneto de don Luis de Frías y Salazar (repárese en el apeliıdo), Lncinas aseguraba que desconocía el nombre del autor y declaraba que, por falta de un manus. crito correcto, tuvo que enmendar más de cien pasajes oscuros: el diálogo era de tan alta calidad que algunos se lo atribuían a León Hebreo. Thomás Gracián Dantısco, en la aprobación, remachaba el clavo: "Parece ser del estilo y lenguage de los otros curiosos de León Hebreo, que andan impressos"'3.

Poderosa recomendación en aquellos días en que Garcilaso el Inca había dado a luz (Madrid, 1590) su elegante versión de los Diálogos de amor del tılósofo judío, acogida con universal aclamación: ya el 31 de diciembre de 1592, en la primera carta al Licenciado Franco -que encontré en el archivo de los Duques de Cadaval y publiqué en la NRFH, 7 (1956), 583-593- confidenciaba: "Desec imprimirlo segunda vez y dividirlo por capítulos". Recomendación que acaso promovió una segunda tirada de Dórida en 1596, si creemos a Nicolás Antonio, único que la cita: al escepticismo convida el que atribuya el escrito a Johannes de Encina, nescio quis, lo quc demuestra que no había leído en los preliminares las reflexiones de Encinas sobre el mérito del diálogo:

3 Para información bibliográfica, cf. José SIMÓN DíAz, Bibliografía de la literatura española, t. 10. Muestra de la confusión reinante es el Manual de Palau, s. v. Enzinas; (Juan de), t. 5, múm. 80158. 
Halléle sin título: y assí no se han podido buscar autor ni registro con quien le concertar. Creo dará gusto por ser la materia tan sutil y discreta quanto gustosa y bien trabajada. Ningún otro encarecimiento sé yo que más le convenga que el que muchos le dan llamándole hijo del doctíssimo León Hebreo, tan recebido de todos en sus diálogos de amor. Lo que de su autor creo, es que mandasse hazer de esta obra lo que Virgilio de su Eneyda, por satisfazerse poco de sí... Yo quisiera hallar el original que dexó escripto, por restituir más de cien lugares que no hazían sentido: helo hecho lo menos mal que he podido.

El Index librorum prohibitorum de Sandoval (Madrid, 1612) prohibió los diálogos de León Hebreo en lengua vulgar, pero no tocó a Dórida. La prohibición se inició en Portugal con el Index auctorum damnatae memoriae de Lisboa, 1624, el cual en la página 114, entre los autores de tercera clase -es decir anónimos- que se vedan, incluye a "Dórida. Hum Diálogo de Amor assi intitulado". De allí gracias a la ósmosis de las dos inquisiciones pasa al Index español de Zapata, Sevilla, 1631, el cual lo consigna con la extraña noticia "Em portugues". Cortesía del Santo Oficio español hacia el portugués, que denuncia el modo mecánico de copiarse unos Índices a otros.

Me propongo examinar la composición, ideas y fuentes de Dórida que pertenece a un género literario oriundo de Italia, nacido a la sombra del platonismo florentino: el tratado de amor.

\section{“DóRIDA" DIÁLOgo DE AMOR. IDEAS Y CONSTRUCCIÓN}

Marsilio Ficino, con su comentario al Banquete de Platón, funda este género híbrido de literatura y filosofía. Está integrado por una serie de hilos que tejen su trama: el comentario a versos de amor, la explicación de mitos, la exégesis de textos escolásticos, el discurso artístico, la discusión de cuestiones o dudas de amor. Si León Hebreo lo mantiene en la cerca de la filosofía, Bembo con los Asolanos lo arrastra hacia la literatura. Aunque gire ordinariamente alrededor del "amor platónico" -fórmula inventada por Marsilio Ficino-, Petrarca suplanta a veces a Platón, de forma que "mucho del llamado platonismo del siglo xv es en realidad petrarquismo" ".

Menéndez Pelayo (Historia de las ideas estéticas en España, t. 2, 1884), ha examinado unos cuantos tratados de amor desde el punto

+ Nesca A. Robs, Neoplatonism of the Italian Renaissance, London, 1935, p. 179. De la copiosa bibliografía pueden consultarse: PAolo LorenzetTI, La belleza e l'amore nei trattati del Cinquecento, Pisa, 1920; JoHn C. Nelson, Renaissance theory of love, New York, 1958. 
de vista privilegiado de la filosofía de la belleza. Esta polarización filosófica es ajena a Damasio, que toma del arsenal filosófico lo que basta para su tema limitado y no se alza, como León Hebreo, a visiones cosmogónicas.

Dórida es un diálogo con cierto ritmo y tensión dramática entre Dameo, a la vez enamorado y maestro, y Dórida, a la vez amada y discípula. Entrecruzamiento normal de didáctica y literatura. Se traba la conversación cuando la muchacha llama a Dameo, que pasa ensimismado sin verla y disculpa su distracción con quejas de amante desamado. Dórida, incrédula, le echa en cara su afectación de "cuando conmigo estás, fingirte muy triste, ponerte muy pensativo, callar a cuanto te digo, como hombre embelesado... en mi ausencia estás con todos muy alegre, riendo y burlando como hombre sin pasión" (Dórida, 281). Dameo con sutilezas alambicadas resuelve esta aparente contradicción, la primera de varias paradojas de amor examinadas a lo largo del coloquio. La muchacha, acosada, revela la verdadera razón de su incredulidad: admira el ingenio de Dameo, aborrece su mudable condición. Porque el poeta ha celebrado y amado sucesivamente a tres damas: a Videna, Fortuna y Galatea, ya olvidadas por él. La justificación de esta mudanza sirve de eje al diálogo.

Dameo asienta el principio de que el amor, si bien nace de la vista de la hermosura, se nutre de la esperanza, necesita de la esperanza. Esperanza de poseer y gozar la cosa amada. Ahora bien, de sus tres amores, "la una hizo mudanza de estado casándose; quien tú sabes, pasó de esta vida; otra está en parte donde no hay esperanza de hablarla ni verla, sino con peligro de su fama y vida" (ibid,. 293). Dórida censura al poeta, porque éste, después de casar Galatea, escribió versos injuriosos contra ella (ibid., 320). Dameo alega que en Galatea hubo, además, un notable desdén, capaz de romper el más fuerte nudo de amor. Dameo irá explicando cómo la muerte, la ausencia y el casamiento de la amada son motivos de justa mudanza, mientras Dórida, por necesidades dialécticas, opondrá los argumentos del amor cortés o del platónico.

Muchos, dice Dórida, afirman que es lícito amar a casadas queriendo de ellas sólo el alma; Petrarca amó a Laura casada y luego muerta; y todos repiten los versos de Boscán "Quien dice que la ausencia causa olvido..." Dameo triunfa fácilmente, distinguiendo entre la ausencia breve que aviva la pasión, y la ausencia sin esperanza, que la mata: corrobora su doctrina con un soneto suyo "Ausente de mi bien, la tierra y cielo / Me son contrarios". En cuanto a Petrarca, no fue siempre amador platónico y espiritual y los muertos son amados únicamente con una sombra o sueño de amor, no con pasión verdadera. Pero la parte más sustanciosa de 
su argumentación es la que expone la imposibilidad moral, virtuosa, de amar a mujeres casadas, impugnando la teoría del amor cortés que lo autoriza. Dórida replica que bien puede existir un amor de casadas sin menoscabo de los derechos del marido; y por otra parte el matrimonio degrada a la mujer, convirtiéndola de señora en sujeta y obediente. Dameo impugna tal concepción del matrimonio: "Yo no veo cómo esto pueda ser, ni donde hallan estos autores que una mujer no deba amar a su marido con toda su alma y vida... No digo yo, Dórida, que cuantos se casan se amen de esta manera; afirmo, sí, que no repugna semejante estado a tal amor" (ibid., 342). Es imposible separar el señorío del cuerpo del señorío del alma, el amor espiritua! del amor corpóreo. "Por ser nosotros puros hombres, es forzoso que sea nuestro amor pmo humano, no espiritual y divino, cual es el de los ángeles" (ibid., 302). "Bien dices, Dórida, cuando nosotros fuéramos puros espílitus desnudos de materia sensual; pero, ¿qué quieres? Que nacimos hombres y es fuerza que nuestro amor sea humano... Digan cuanti) quisieren los muy contemplativos de amor, aquellos todos cuantos tienen descarnados sus deseos; que cuantos fueren hombres, han de amar como tales, pues lo demás, Dórida, es sustentarse del aire, como camaleones. Que yo ver quiero siempre conmigo y en mi presencia lo que amo" (ibid., 313). "Mira, Dórida, quiero repetirte lo que ya otras veces te he dicho, que yo, cuando amo... no amo el cuerpo solo, no sola el alma y por sí: el todo es el amado. Yo a Dórida quiero, a Dórida amo, y Dórida es su alıa y cuerpo junto, no cualquiera de ellos" (ibid., 333).

Basten estos trechos para mostrar con qué insistencia rechaza no solamente el amor cortesano que disocia el cuerpo, propiedad del marido, del alma, disponible para el amante, sino también el amor platónico, para el cual las criaturas con su belleza corpóreoespiritual son simples escalones que guían el alma en su ascensión hacia la suprema belleza incorpórea. Para Dameo la criatura mixta de cuerpo y alma es la meta y objeto del amor.

No acaba aquí el coloquio que se desvía hacia los remedios del amor. Dameo reseña las curas que proponen Ovidio, los médicos y los filósofos platónicos, hallándolas ineficaces para el amor verdadero. Únicamente el desdén, consistente en alguna "notable y grande ingratitud y afrentoso desprecio", triunfa del poder del amor. Y confirma esta doctrina con dos sonetos propios en que pinta la lucha del amor con el desdén, y el triunfo final del desdén.

Dórida amalgama variados ingredientes: citas de poemas, disquisiciones filosóficas de sabor aristotélico, interpretación de mitos paganos, como el de Orfeo y Eurídice, el de Minotauro. Todos están manipulados para servir a la alegoría moral, y uno -el del 
origen del Desdén, que empalma con la fábula platónica de Andrógino- me parece simple invención del poeta.

\section{Las fuentes italianas: León Hebreo}

No se engañaban los contemporáneos asociando a Dórida con los diálogos de León Hebreo, cuya influencia es tan clara como superficial. Se reduce a la imitación de dos procesos artísticos, y quizá a un menudo polvillo de conceptos poco característicos: unos vienen de Aristóteles, otros forman la tópica de los tratados de amor, otros acaso originados en la lectura de León Hebreo, son aplicados con espíritu diferente.

1) El encuentro de Dameo y Dórida, que pone en movimiento el coloquio, se inspira en el comienzo del Diálogo segundo de Sofía y Filón. Filón (León Hebreo, 356) abismado en sus cavilaciones filosóficas, pasa de largo sin ver a Sofía que le interpela irónicamente:

Sophia: O Philon, ¿no oyes o no quieres responder? Philon: ¿Quién me llama? Sophia: No te passes assí tan de prissa; escucha un poco. Philon: O Sophia, ¿aquí estavas? inadvertidamente passava. Sophia: ¿Dónde vas con tanta atención que no hablas, ni oyes, ni vees los circunstantes amigos?

Y a continuación se queja de que Sofía no le ama. Compárese con Dórida:

Dórida: ¿Dónde bueno, Dameo, tan pensativo y fuera de ti [Burgos, 1593: "de tino"], que no echas de ver quién te llama? Dameo: Iba pensando cuán sin ventura me hizo el cielo, y a ti cuán sin piedad.

Sospecho que a la imitación de León Hebreo se asocia el recuerdo del coloquio erasmiano Procus et puella, o Coloquio del matrimonio, donde hablan María y su pretendiente Pánfilo. Dórida con sus incredulidades y su progresivo ceder se parece más a María que a Sofía. Y ni Dameo ni su amada acaban siendo abstractos exponentes de la conversación como los dos personajes de LEÓN HEBREO ${ }^{5}$.

2) Damasio, igual que León Hebreo, prodiga las fábulas mitológicas: la del Minotauro (Dórida, 335-336) a la que busca una alambicada exégesis moral; la de Orfeo y Eurídice (302-907) en que Eurídice simboliza el alma, cosa que viene de lejos y se en-

"La versión de Procus et puella está incluida en Origenes de la novela, t. 4, pp. 163-171. Comentario y versión moderna inglesa en The Colloquies of Erasmus, tr. by C. R. Thompson, Chicago and London, 1965, pp. 86-98. Sobre su fortuna en España of. M. Bataillon, Erasmo y España, México, 1966. 
cuentra hasta en la Mythologia de Natalis Comes; la de Andrógino, única común con León Hebreo, el cual la lleva por caminos muy diferentes (León Hebreo, 410-411: Dórida, 365-369); y la del Centauro (334) que, como veremos, deriva formalmente de Sperone Speroni. Ya es sabido que Marsilio Ficino y otros florentinos, entusiasmados con los mitos de Platón, hallaron en las fábulas mitológicas secretos de teología y filosofía, visibles tras el velo transparente de la poesía ${ }^{6}$. Y que León Hebreo señala la pleamar de esta tendencia, ya que dedica muchas páginas a alegorizar las fábulas del origen y amores de los dioses de Grecia y Roma, encontrando en algunas, por ejemplo la de Andrógeno [sic], resonancias y reflejos de la Biblia. Mientras para León Hebreo la mitología es un atisbo de la revelación primitiva, para Damasio constituye un elemento decorativo, un campo de ingeniosas moralidades.

3) No voy a particularizar las abundantes coincidencias de Dórida con León Hebreo que remontan a una tópica mostrenca del tratado de amor: que el amor nace de la belleza y busca el gozo en la posesión. Que el amor incluye la esperanza, está dicho de paso en Lorenzo de Médicis y en otros, aunque nadie lo ha situado en el centro de la exposición, como Damasio. León Hebreo (287) distingue, no sé a la zaga de quién, entre amor real e imaginario, amor de cosa real o fingida, distinción que cobra bastante importancia en Dórida.

León Hebreo suplementa con ideas del Estagirita su platonismo básico. Ya su traductor Garcilaso el Inca notaba en una breve adición final "la intención de aquel Hebreo más platónica que aristotélica”. Damasio, por el contrario, es un militante de Aristóteles, siempre dispuesto a pregonar su amor que no cejó hasta los últimos diálogos. Se confiesa (Lenguas, 25l) "aficionadísimo a la doctrina aristotélica". Aun en materia de lenguas él se alineaba del lado del aristotélico Pietro Pomponazzi, compartiendo las opiniones que, bajo la máscara de Peretto, le atribuye Sperone Speroni ${ }^{7}$.

6 Cf. Jean Seznec, La survivance des dieux antiques, London, 1940; Don Cameron Allen, Mysteriously meant. The rediscovery of pagan symbolism and allegorical interpretation in the Renaissance, Baltimore and London, 1970.

7 Que Peretto es Pomponazzi (Pietro) no ofrece duda; cf. Bruno MiglioRINI, Storia della lingua italiana, Firenze, 1960, p. 320; Giacinto Marciotta, Le origini italiane della "Querelle des anciens et des modernes", Roma, 1953, pp. 104-110. Pomponazzi sostiene que es preciso romper con el abuso de explicar la filosofía en latín, traduciendo a Aristóteles, pues todas las lenguas son de igual dignidad y capaces de los misterios filosóficos. Idea aceptada por Speroni, sostenida por Diego Hurtado de Mendoza, y defendida por Damasio en Lenguas. La opinión de Hurtado de Mendoza está recogida por Paulo Manuzio en su dedicatoria a D. Diego de M. Tullii Ciceronis De philosophia, Venecia, 1541, cf. González Palencia-Mele, Vida y obras de D. Diego Hurtado de Mendoza, t. 3, Madrid, 1943, p. 271. 
Pero quede esta faceta para los historiadores de las ideas lingüísticas. En materia de amor, por motivos éticos, se inclinaría al platonismo. Muestra repugnancia por "los amores másculos que, como locura y maldad, tanto abo[mi]naba Aristóteles, y tanto, por el contrario, los celebraba su maestro Platón" (Discreción, 128). Su interlocutor Lucio, animándole a exponer sus ideas de aficionado y dándole irónicamente la alternativa "como filósofo que sois", liga aristotelismo y cristianismo: "Pues aunque Aristóteles no fue tan virtuoso, digámoslo ansí, como Sócrates o Platón, que yo por más le tuve siempre que a entrambos, no por eso le estuvo mal enseñar al mundo aquellas divinas Éticas y Políticas, antes [es] sumamente loado por esta particular doctrina de costumbres, con que tanto ayudó a las nuestras cristianas" (ibid., 199).

\section{LAS FUentes italianas: SPERoni y VARchi}

Anticipemos que Dórida no encierra ni plagios ni imitaciones descaradas, aunque sí denuncia el placer juvenil de respirar una atmósfera de cultura y reaccionar frente a sus lecturas. No dudo que leyó al Bembo, cuyos Asolanos se imprimieron en Salamanca traducidos (1551) en sus probables años de estudiante; que hojeó el indigesto y mal escrito Libro di natura d'amore que Cervantes (Galatea) y otros contemporáneos espigaron en los estiajes de las musas ${ }^{8}$. Alude claramente con ironía al Cortesano de Castiglione al discutir si los amantes "apurados y finos" pueden, como insinuaba el Bembo, tomarse ciertas libertades "un darse las manos, un abrazo, una amorosa paz, que hasta esto todo bien dan licencia los muy contemplativos" (Dórida, 344). Cita sin autor el título de un libro raro: "No es verdad averiguada que pueda enamorar la fama, aunque lo diga el Petrarca y lo quiera probar el autor de aquel diálogo llamado Aretifila" (Dórida, 310). Acaso recordaba mal, pues si la primera parte de la Aretitila de Luc'Antonio Ridolfi (Lyón, 1560) admite el enamorarse por fama, la segunda lo refuta. Creo que su única fuente italiana importante es Sperone Speroni, y sospecho que tomó notas de Varchi.

Dórida se hacía portavoz del amor platónico, defendiendo la famosa escala en que la belleza corporal servía únicamente para elevarse a la contemplación de la belleza espiritual: "El amor de estas cosas corpóreas no ha de servir ni durar más de llevarte a las del alma, y, aquellas vistas y conocidas, olvidarte de estas groseras y sensibles”. A lo que replica Dameo: “Guarda, señora, que eso

8 Sobre las deudas de Cervantes con los tratados de amor, cf., F. Lóprz Estrads, La "Galatea" de Cervantes, La Laguna, 1948, pp. 85-95. 
es imposible! $\mathrm{Y}$ en efecto es querer que, estándote yo mirando, no te vea, ni mis ojos reciban contento viendo tu divina belleza; que, como elegantissimamente dice el doctissimo Speron, querer gozar de sola el alma, sin hacer caso del cuerpo es comer la vianda sin mascar, que no la puedes pasar; y, si algo comes de esta manera, no te aprovecha a la nutrición" (Dórida, 333: Speron1, f. 16r). Y más adelante, discutiendo los emblemas y pinturas del amor, remata: "Oye la nueva del divino Speron, que a un tan grande dios le pintó hecho Centauro, con el medio cuerpo de caballo y, de la mitad arriba, de hombre... Y lo que esta figura pretende, es, Dórida, mostrarnos que tiene una parte sensual, común con los demás animales, que es amor del cuerpo; otra racional y humana propia del hombre" (Dórida, 333: Speron1, f. 16v).

De Speroni toma diferentes ilustraciones y fórmulas: 1) la comparación de la esperanza con la cera de una candela: "Verás que nuestro amor es como el fuego de una vela, el cual no dura más de cuanto el húmedo de la cera, y, éste acabado, espira a la hora aquella llama. Así pues amor, verdadero fuego de nuestras almas, no dura más de cuanto le acompaña y da fuerza la dulcísima esperanza, que si ésta falta, luego amor se disuelve y acaba". "Il desiderio amoroso è veramente, qual noi diciamo, fiamma e ardore: e questo, come s'accende in un punto, cosi im un punto si spegnerebbe, se la speranza non lo vietasse: nella quale, come il fuoco nella candela, si converva il nostro appetito" (Dórida, 290: SPEron1, f. $5 \mathrm{v})$. 2) La comparación del amor naciente con el oso mal lamido, que al nacer es un pedazo de carne sin forma, al que su madre modela con la lengua, conseja en la que hasta el escéptico Francisco Sánchez autor del Quod nihil scitur creía en aquel tiempo (Dórida 360: Speron1, f. 27v) . 3) La pintura irónica de los amantes de sola el alma: "Atrás te dije, señora, que un tal amor como ese y tan descarnado, que era puro, angélico y espiritual, de solos aquellos entendimientos desnudos de materia cuales son los ángeles". Reminiscencia probable del ataque a los que menosprecian los deleites del mundo, que dice entre otras cosas: "Questa sarebbe operatione non d'huomo, ma d'angelo, il quale è puro intelletto senza corpo" (Dórida, 332: Speronı, f. 27v).

Pienso que leyó a Benedetto Varchi, seguidor y amigo de Speroni. Varchi ha sido profesor en la Academia florentina de Cosme de Médicis donde recitó en 1553 una lección de amor comentando el soneto de Petrarca "S'amor non è, che dunque è quel ch'i'sento", y más tarde cuatro lecciones Sopra alcune questioni d'amore. Acaso Damasio tomó de la lección de amor algunas de sus reflexiones sobre el carácter muy humano, nada espiritual de ciertas poesías amorosas del Petrarca, quién sabe si algún ejemplo como el de 
la famosa sextina I con la estrofa "Con lei foss'io da che si parte il Sole". Deuda baladí si la hay. Hace sospechar que empleó material de Varchi el que 20 "questioni d'amore" reaparecen en Dórida por lo menos cinco: la 1a, "Qual sia più nobile, o l'amante, o l'amato"; la 6a., "Se alcuno può innamorarsi, o amare senza speranza"; la 8a, "Se alcuno può solo per fama e d'udita innamorarsi"; la 13a, "Se l'amore può sanarsi in alcun modo"; la 16", "Se morti possono amare, o essere amati". La difusión en Italia de las preguntas o dudas (questioni, dubbii) amorosas, vulgarizadas por el Filócolo de Boccaccio en la famosa escena del jardín junto a Nápoles, adoptadas por los tratados de amor, los poetas y novelistas, alcanzó proporciones de epidemia social en saraos y academias ${ }^{9}$. Penetró en España con la novela de ambiente napolitano Questión de amor que Garcilaso rememoró en su Egloga primera, se insinuó en la Diana de Montemayor, en la Selva de aventuras de Jerónimo de Contreras, y tocó de ligero a Lope de Rueda y Juan Timoneda. Damasio, el mayor tributario de esta moda, manoseó quizá las propuestas en las lecciones de Benedetto Varchi, pero trató el material a su aire, intercalándolo diestramente en el coloquio.

\section{Lugar de Dórida en la obra de Damasio}

Podemos datar con precisión los otros diálogos. Discreción fue acabado el 17 de agosto de 1579, según reza el explicit, Lenguas fue compuesto a continuación, probablemente el mismo año. En cuanto a Alabanzas de Valladolid ${ }^{10}$ el más reciente historiador social de la ciudad lo fecha en 1582, sin duda basándose en los datos internos. Dórida puede atribuirse conjeturalmente, sin concretar más, al final de la juventud y aprendizaje de su autor, si interpretamos por su valor nominal ciertas autocríticas en Discreción.

Dórida asegura que la boda de Galatea y los versos injuriosos de Dameo eran historia fresca. Damasio no pierde ocasión de ingerir en el coloquio sus propios versos y aun sus versiones frag. mentarias de Petrarca, mostrando apreciar altamente la gloria de poeta. La obra entera está escrita para probar que la plural historia de sus amores no se debe achacar a inconstancia de su corazón y que se compagina con la más alta nobleza de comportamiento moral. En cambio, en 1579 Damasio profesa haber dejado atrás las aficiones poéticas de su mocedad y -sinceridad o hipocresía- desdeña sus versos:

9 Cf. T. F. CRANe, Italian social customs of the fifteenth century, New Haven, 1920, libro riquísimo en noticias tanto de la literatura italiana como de la española.

10. Véase Bartolomé Bennassar, Valladolid au siècle d'or: una ville de Castille et sa campagne au xuie siècle, Paris-La Haye, 1967, pp. 126 y 139. 
Me acaece a mí con algunos en esta villa que a la fama de que yo algún tiempo, cuando más mozo, movido de mis particulares gustos, hice ansí no sé qué niñerías de poesía, nunca hacen sino cansarme con loores de mis poesías... importunándome que se las muestre, sin que con ellos -digo cierto verdad en esto- me valga muchas veces jurar y perjurar que nunca de esta arte traté, como ello es verdad, con atención y propósito de ser en ello conocido, ni de que jamás hombre viesse cosas mías, las quales sabéis vosotros muy bien que, si algunas andan esparcidas por Castilla, nunca fue dándolas yo ni pretendiendo mostrarlas (Discreción, 97).

Cuando en 1579 miraba hacia su carrera de prosista, confesaba que en su mocedad pecó de excesivo fervor por la literatura italiana. En su lectura se había contagiado de dos vicios: de una excesiva frondosidad verbal, y del gusto por las digresiones. Ahora, acaso por el ejemplo del Lazarillo y de Diego Hurtado de Mendoza que en su Guerra de Granada ponía la proa hacia la concisión de Salustio y Tácito, procuraba podar tales exuberancias. He aquí el texto de su autocrítica: "Yo que del ingenio español conozco cuán amigo es de la substancia dicha con brevedad en cualquiera cosa que se trate, y cuánto se enfada con la superflua copia de palabras, con que tanto dilatan y extienden algunos extranjeros sus escritos y conceptos, no querría dar en vicio con que yo tan mal estoy, después que ya una vez pude librarme del que pegado se me había en mis primeros años de la continua lectura e imitación de autores italianos [...]. Anduvo en esto por cierto tan discreto como docto el Casa, que jamás desmamparó su principal propósito con digresión que de veinte renglones pase y muy a cuento no viniese" (Discreción, 134-135). Dórida, a mi ver, se encuentra a medio camino entre los escritos de juventud y los de 1579. Si su gravitación hacia los modelos italianos es muy grande, y su razonar discurre entre meandros y digresiones, en cambio poco se diferencian en el gusto por la amplificación y el saboreo moroso del lenguaje. Quizá los escritos primerizos serían menos sobrios aún. La locuacidad de Damasio deriva a mi entender de su tentativa de hermanar el fluir libre de la conversación con el movimiento del diálogo ciceroniano: redoblamientos de sinónimos, cadencias y simetrías discretas, párrafo amplio en el cual quepa un pensamiento con todas sus circunstancias. Es un ideal que ni en sus escritos de 1579 abandona por completo, aunque va restañando el flujo. Su atención admirativa prefiere ahora modelos como Giovanni della Casa cuyo Galateo cita repetidamente, ya por su temática ya por su elegancia sobria ${ }^{11}$.

11 Sobre Della Casa y su Galateo, véase Lucas Gracián Dantisco, Galateo español, Madrid, 1968 (Clásicos hispánicos), con estudio preliminar muy erudito, notas y glosario de Margherita Morreale. 


\section{DAMASIO hidalgo POBRe, PENSAdor LEgo}

Damasio pertenece a la clase social de hidalgos pobres que han de arrimarse a los grandes señores para vivir. Aunque cursó estudios en Salamanca, quién sabe si como acompañante de un noble, no eligió ni la carrera de la iglesia, ni la de la administración. Sirvió al almirante Luis Enríquez que le intentó quitar los resabios escolares y en cierto modo hizo de él un cortesano: "Bien como si entre mis iguales estuviera en las escuelas de Salamanca, voceaba y me metía tan de veras en cólera que vosotros, viéndome tan puro estudiante entre señores y con ellos, no pudiérades menos que reíros de mi necedad. Decíame el Almirante, mi amo... riendo y con aquella su admirable bondad: «Damasio, muy porfiado sois». No entendía yo, como bozal estudiante, puro escolástico, que aquello era llamarme necio con término comedido" (Discreción, 161162). Por más que su amo le tratase con aprecio y gustase de su compañía, Damasio de mala gana sujetó el cuello al yugo de la servidumbre. Cuando en 1572 falleció el Almirante, Damasio supo lo que era la pobreza "no mansa, como dice el poeta castellano [Mena], sino muy brava y estrecha" (Discreción, 123). Si Dórida fue, en gran parte, sacada de libros, luego aprendió en el amargo libro de la experiencia y escribió aceradas páginas sobre las desventuras del hidalgo pobre y el tema de nobleza es riqueza. Un par de veces parece glosar el Lazarillo, por ejemplo, cuando desarrolla la máxima "por incompatible junta tuve yo siempre honra y pobreza" (ibid., 142-146). Extracto un breve fragmento: "Insufrible me parece la ignorancia, o llamémosla ansí, la necedad de algunos pobres hidalgos que nunca andan sino quebrando la cabeza a cuantos tratan y, donde quiera que se hallan, y a cualquiera propósito o sin él, con su hidalguía y nobleza. «No, eso no me hablen, que a fe de hijodalgo que con esta pobre capa me hago yo estimar en tanto como cuantos judíos hay con todas sus riquezas». «No, yo le juro a v. md. que, si primero no me quita la gorra, que no la lleve de mí por más cuentos que tenga de renta». «No, no: bien sabe el mundo todo quiénes fueron mis pasados»... Debríamos los pobres, los que Dios fue servido que lo fuésemos, dejar la vanidad de estas jactancias y presunciones, acomodándonos al tiempo y necesidad presente".

Cuando Damasio recapacitaba sobre su historia, decía a sus amigos: "Sabéis vosotros, lástima grande, la perdición de mi vida y tiempo tan mal gastado" (Discreción, 74). Aunque frecuentaba a los universitarios y a los frailes de Santa María de Prado, él se consideraba hombre de capa y espada: "Me reí yo mucho algún día, delante nuestro amigo Francisco de Figueroa, de cierto hombre 
tenido por docto, y con razón", el cual alababa mucho un libro que cierto amigo romano componía acerca de los orígenes de nuestra lengua. Damasio, después de mostrarle la vanidad de sus etimologías, concluye: "No tuvo él entendido al principio que, entre las capas y espadas que allí estábamos, hubiera alguna que se atreviera a su bonete" (Lenguas, 254-255).

Aunque pasaba su vida en conventos y palacios, no abdicó de su independencia de juicio. "No me parece a mí mal que vos o cualquiera otro seáis en las cosas indiferentes y dudosas amigos de vuestra opinión. . He visto yo algunos que se rieron muy de veras de mí en algunas partes, por sólo que no seguía sus opiniones en esto, pareciéndoles que no debía tener yo libertad de entendimien. to" (ibid., 275). "Dejemos, si os parece, la autoridad de esos y de cuantos más lo dijeren, y vengamos, si sois servido, a sus razones" (ibid., 215).

Esta independencia de espíritu guarda relación, a lo que pienso, con su condición de hidalgo pobre que, confinado en servidumbres sociales se refugia en la convicción íntima del valor decisivo e intrínseco de la persona. “¿Cómo sufrirá el hidalgo español, nacido y criado con una libertad nobilísima y con un ánimo exento y tan brioso en toda su pobreza verse maltratar o estimar en poco?" (Discreción, 178). Damasio aplicaba este ánimo exento al análisis de los problemas de la sociedad y la cultura. Y por ello combate contra opiniones recibidas del vulgo y de los intelectuales sin amilanarse y discurriendo por cuenta propia. Sus diálogos, no acabados de limar y no impresos en su tiempo, anticipan posiciones intelectuales venideras. Traza por vez primera un modelo de discreto adelantándose a las aspiraciones del siglo siguiente ${ }^{12}$. Y contra viento y marea, en "Diálogo de las lenguas", aprovechando las sugestiones de Speroni y de Hurtado de Mendoza, y coincidiendo en otros puntos con Joachim du Bellay (al que parece aludir en pp. 224, 233) proclama el valor de las lenguas vulgares para la especulación filosófica. Damasio, excelente latinista y conocedor del griego reacciona contra la superstición universitaria de que los misterios del pensamiento sólo caben en el cauce de las dos lenguas antiguas.

Eugenio Asensio

Lisboa.

12 Acerca de "discreción" y su campo semántico véase Margarit J. Bates, "Discretion" in the works of Cervantes: A semalic study, Washington, 1945, que tiene escaso interés para mi propósito. 